\title{
Automatic cephalometric landmark identification in lateral skull X-Rays using convolutional neural networks
}

\section{Localización automática de etiquetas cefalométricas en radiografías laterales de cráneo utilizando redes neuronales convolucionales}

\author{
LÓPEZ-RAMÍREZ, José Luis',",*†, CALDERÓN-SASTRE, Enrique', QUINTANILLA- \\ DOMÍNGUEZ, Joel" and AGUILERA-GONZÁLEZ, José Gabriel"
}

'Universidad de Guanajuato, Electronics Engineering Department, Salamanca, Mexico.

"Universidad Politécnica de Juventino Rosas, Juventino Rosas, Mexico.

ID $1^{\text {st }}$ Author: José Luis, López-Ramírez / ORC ID: 0000-0001-7225-6556

ID $1^{\text {st }}$ Co-author: Enrique, Calderón-Sastre / ORC ID: 0000-0002-2519-242X

ID $2^{\text {nd }}$ Co-author: Joel, Quintanilla-Domínguez / ORC ID: 0000-0003-2442-2032

ID $3^{\text {rd }}$ Co-author: José Gabriel, Aguilera-González / ORC ID: 0000-0002-4160-448X

DOI: $10.35429 /$ JEA.2021.25.8.1.9

Received: January 10, 2021; Accepted: June 30, 2021

\begin{abstract}
Cephalometric analysis is a study held in orthodontics, based on the identification of certain points in a skull image obtained through an X-ray image or another method in medical imaging. The indicated points are compared with standard values to evaluate and diagnose the patient. The radiograph's labeling is regularly performed by hand, which makes the labeling process slow and prone to errors due to the visual acuity required. This approach is not much reproducible, because it relies on the domain and expertise of the expert labeler. Many machine learning methods were successfully applied to solve medical imaging tasks, aiming to reduce the health experts' workload and emit more accurate diagnoses in less time and, avoid a more several clinical case. This work shows the design and development process of a machine learning system based on convolutional neural networks to identify 19 cephalometric landmarks for a lateral skull radiograph image as input. The system used a 400 labeled images dataset, from which, 150 were used for training, 150 for model's validation and it was tested in the 100 remaining images.
\end{abstract}

Cephalometric analysis, Deep learning, Convolutional neural networks

\begin{abstract}
Resumen
El análisis cefalométrico es un estudio realizado en ortodoncia, basado en la identificación de puntos en una imagen del cráneo obtenida mediante radiografía o por otro método de imagenología. Los puntos ubicados son comparados con valores estándar para la evaluación y diagnóstico del paciente. El etiquetado de las radiografías se realiza regularmente de manera manual, lo cual lo hace lento y susceptible a errores debido a la agudeza visual requerida. Este enfoque es poco reproducible ya que depende del dominio y criterio del experto que etiqueta. Diversos métodos de aprendizaje de máquina se han aplicado de manera exitosa a tareas que involucran imágenes médicas, buscando reducir la carga de trabajo de los profesionales de la salud y emitir diagnósticos más certeros en menor tiempo y, que eviten un cuadro clínico más grave. Este trabajo muestra el proceso de diseño y desarrollo de un sistema de aprendizaje automático basado en redes neuronales convolucionales para la identificación de 19 etiquetas cefalométricas para una radiografía lateral de cráneo como entrada. El sistema utilizó un conjunto de datos 400 imágenes etiquetadas de las cuales, 150 se utilizaron para entrenamiento, 150 para validación del modelo y se probó en las 100 imágenes restantes.
\end{abstract}

Análisis cefalométrico, Aprendizaje profundo, Redes neuronales convolucionales

Citation: LÓPEZ-RAMÍREZ, José Luis, CALDERÓN-SASTRE, Enrique, QUINTANILLA-DOMÍNGUEZ, Joel and AGUILERA-GONZÁLEZ, José Gabriel. Automatic cephalometric landmark identification in lateral skull X-Rays using convolutional neural networks. Journal of Engineering Applications. 2021. 8-25:1-9.

\footnotetext{
* Correspondence of the Author (Email: jl.lopezramirez@ugto.mx)

$\dagger$ Researcher contributing as first author.
} 


\section{Introduction}

The cephalometric analysis is an essential tool in orthodontics. It allows physicians to detect related craniofacial pathologies, orthodontics diagnoses, or maxillofacial surgery planning. The cephalometric analysis makes use of lines traced in skull radiographs to make both linear and angular measurements that will be compared against standard values. To trace the lines is necessary to label the radiograph with the required cephalometric landmarks to accomplish the corresponding study.

There exist as many cephalometric landmarks as necessary, new landmarks can be created if they fulfill two conditions (Rakosi, 1982): Easy to locate it (aiming that radiograph's quality and overlapping anatomic tissues have the least possible impact), and that the landmark's location have little influence by sex, race or age aspects. Cephalometric analysis has many diverse applications. In the orthodontics field there are four main applications (Kula \& Ghoneima, 2018):

- Malocclusion.

- Brute inspection: To emit a general landscape about the morphology of maxillofacial structures.

Treatment generation based on craniofacial evaluation.

- Growth analysis and evaluation of previous treatments: This analysis is possible due to the cephalometric analysis' reproducibility and the capability of cephalograms to overlap it.

In addition to the orthodontics applications, cephalometric analysis can reveal important information about other pathologies like (Athanasiou, 1995): Identification of some pathologies in the pituitary gland, or abnormalities in skull, mandible, cervical spine, or maxillary and paranasal sinuses.
Although cephalometric analysis is a mandatory step in most orthodontics treatment and diagnosis, the labeling process in cephalometric analysis is mostly carried by hand, which makes it prone to detection and interpretation errors caused by limitations in the eye-brain human system, presence of overlapping structures that hide relevant features to the study (Giger et al., 2008), labeler's fatigue or lack of expertise.

Lateral Cephalometric Radiographs (LCR), also known as cephalographs, is a $2 \mathrm{D}$ radiograph that favors visualization of teeth, cranial bones, and soft tissue. The LCRs are used to carry cephalometric analysis. Figure 1 shows an example of LCR.

With the demand for medical services and diagnoses, the physicians need more tools to automate or reduce the times of certain processes. The implementation and use of Computer-Aided Diagnosis (CAD) systems allow early detection and progress measurement of certain pathologies, and at the same time, reduce the image-reading times. The CAD systems serve as a second opinion to the physician, this in a complementary way to reinforce or refute the initial hypothesis regarding the study in turn.

The first CAD system approved by the Food and Drug Administration in 1998 (Freer \& Ulissey, 2001), the system detects lesions in mammographs. By 2016, 92\% of the mammograph screening involved some CAD system (Fujita, 2020).

The aim of this work is to create a CAD system that can reduce the physicians' workload by identifying 19 cephalometric landmarks from a digital cephalograph as input, using a Convolutional Neural Network to find the (x,y) coordinates of each landmark. The landmarks were selected according to the only public database available, which is the one released during the IEEE International Symposium on Biomedical Imaging 2015 (IEEE ISBI 2015). Table 1 provides the names of the landmarks used in this work. Figure 2 shows the location of the cephalometric landmarks used. 


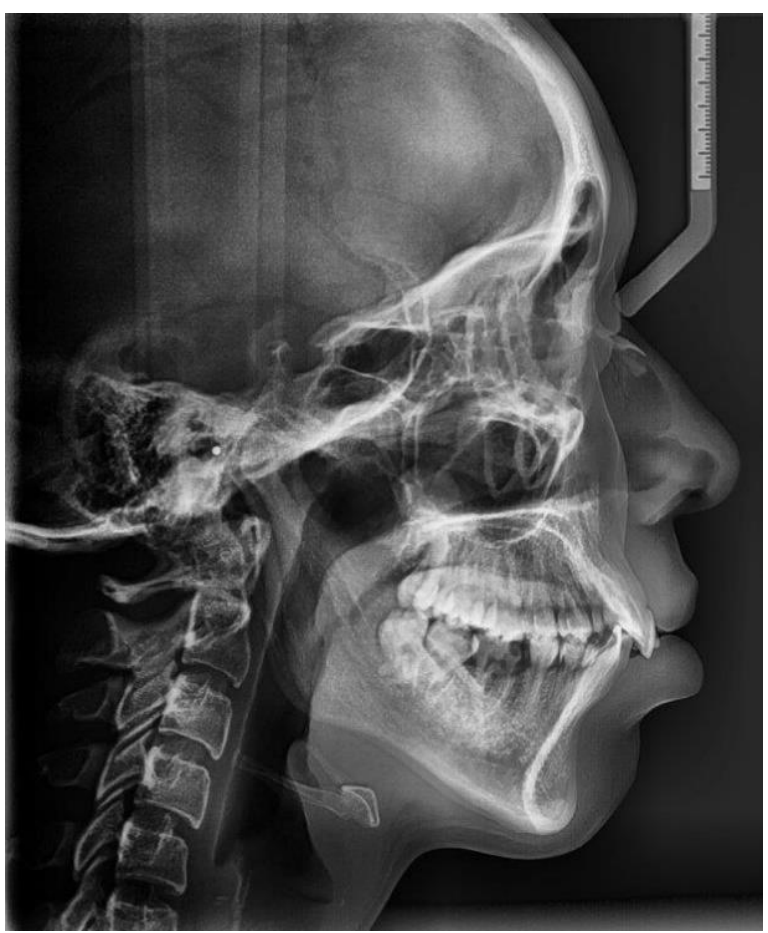

Figure 1 Example of a lateral cephalometric radiograph

\begin{tabular}{|r|l|}
\hline \multicolumn{1}{|r|}{ Identifier } & \multicolumn{1}{|c|}{ Landmark } \\
\hline 1 & Sella turcica \\
\hline 2 & Nasion (N) \\
\hline 3 & Orbitale (Or) \\
\hline 4 & Porion (P) \\
\hline 5 & Subspinale \\
\hline 6 & Supramentale \\
\hline 7 & Pogonion (Pog) \\
\hline 8 & Menton (Me) \\
\hline 9 & Gnathion (Gn) \\
\hline 10 & Gonion (Go) \\
\hline 11 & Lower incisal incision \\
\hline 12 & Upper incisal incision \\
\hline 13 & Upper lip \\
\hline 14 & Lower lip \\
\hline 15 & Point PM or MN \\
\hline 16 & Soft tissue pogonion \\
\hline a & Posterior nasal spine \\
\hline b & Anterior nasal spine \\
\hline AR & Articulate \\
\hline & \\
\hline
\end{tabular}

Table 1 Name of the 19 cephalometric landmarks to label with the system presented

Source: Adapted from (Athanasiou, 1995), (Gill \& Naini, 2011), (Foster, 1990), (Cardillo \& Sid-Ahmed, 1994), (Leonardi et al., 2009)

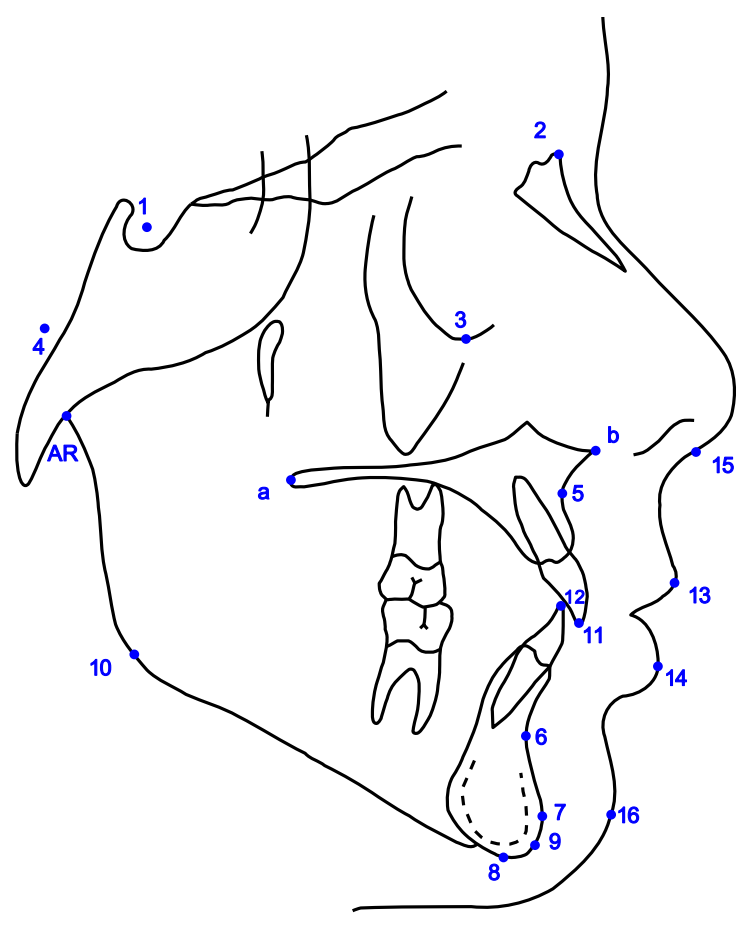

Figure 2 Location of the 19 cephalometric landmarks Source: Adapted from (Wang et al., 2015)

\section{Related Work}

In addition to the new capture techniques, cephalometrics has taken advantage of the available computational tools, an example of this is the use of tools to automatically trace the cephalograms and CAD systems that help physicians to take decisions regarding treatments.

We can classify the CAD systems for cephalometric landmark detection into three main categories (El-Feghi et al., 2004):

- A mix of image processing techniques to extract relevant edges to the landmarks.

- Geometric techniques with edge detection based on template matching coded with previous knowledge to reduce the region of interest.

- Computational intelligence techniques.

Below are some representative CAD systems for cephalometric analysis according to the categories presented above:

The first CAD system applied to cephalometric analysis was developed in 1986 by Lévy-Mandel et al. (Lévy-Mandel et al., 1986). 
The system proposes a system with a pre-processing step, followed by edge detection, and a priori coded algorithm to follow the most characteristic lines where cephalometric landmarks are commonly located. The system works in $256 \times 256$ gray-scale cephalograms.

In 1994, Cardillo and Sid-Ahmed (Cardillo \& Sid-Ahmed, 1994) presented a system based on mathematical morphology to be applied in gray-scale images. The system was trained using 40 images and obtained an $85 \%$ detection rate in 20 landmarks.

In 1999, Chen et al. (Chen et al., 1999) presented the first CAD system for cephalometric analysis based on neural networks and genetic algorithms. The system uses a multi-layer perceptron with a neuron in the last layer to indicate if there is a similarity between the output and the pattern to identify.

In 2004, El-Feghi et al. (El-Feghi et al., 2004) presented a similar features clustering algorithm connected with a neuro-fuzzy block to get an estimated location and refine the results using template matching techniques.

In 2014, the Automatic Cephalometric X-Ray Landmark Detection Challenge was hosted during the IEEE International Symposium on Biomedical Imaging. In this challenge, the organizers provided a 300 images dataset. The dataset included the location of the 19 cephalometric landmarks shown in Table 1 for each cephalogram. None of the five first places used a neural network-based approach. The winner of the challenge (Ibragimov et al., 2014) used an approach based on game theory and random forest to obtain $72.2 \%$ in the $2 \mathrm{~mm}$ range. One year later, in the IEEE ISBI 2015, another challenge was carried out. In this edition of the challenge, the organizers provided a bigger public database with 400 images, labeled with the location of the 19 landmarks shown in Table 1 . The $1^{\text {st }}$ and $2^{\text {nd }}$ places of the challenge (Lindner \& Cootes, 2015) and (Ibragimov et al., 2015) used approaches based on random forests. In recent years, computational intelligence techniques have shown the best results in solving this challenge. For a more extensive revision and comparison of recent CAD systems in cephalometric landmark detection, please see (Lopez-Ramirez et al., 2020).

\section{Methodology}

The approach used to solve the problem is the use of convolutional neural networks to create a regression model to predict the $(\mathrm{x}, \mathrm{y})$ coordinates of the 19 landmarks of the input image. In literature, this approach is known as Vanilla deep regression, in which the final layer of the architecture performs the regression. Figure 3 shows the diagram of an architecture of a convolutional neural network that makes a regression.

\section{Dataset}

The dataset used contains 400 labeled cephalograms. The images were labeled twice by two expert orthodontists with six and 15 years of experience. For each of the labeled images, a plain text file was provided. The file includes the $(\mathrm{x}, \mathrm{y})$ coordinates of each of the 19 cephalometric landmarks. The ground truth of the location is the average of the labels made for each coordinate. Table 2 shows the characteristics of the database used.

\begin{tabular}{|c|c|}
\hline Feature & Value \\
\hline Machine receptor & $\begin{array}{l}\text { Soredex CRANEX Excel Ceph } \\
\text { machine }\end{array}$ \\
\hline Patient's age & Between 6 and 60 years. \\
\hline Resolution & $1935 \times 2400$ pixels. \\
\hline Output format & TIFF \\
\hline Pixel size & $(0.1 \times 0.1) \mathrm{mm}^{2}$ \\
\hline Training images & 150 \\
\hline Test images & 250 \\
\hline
\end{tabular}

Table 2 Main features of the used database.

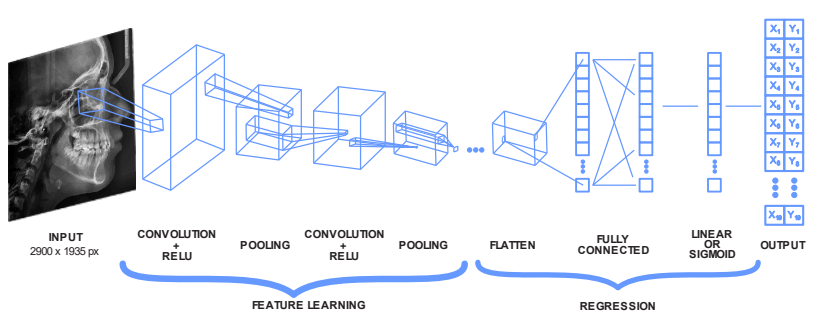

Figure $3 \mathrm{CNN}$ schematic used for vanilla deep regression

The images in the database were randomly split into three datasets: The training set containing 150 images, the validation set (Test1) with 150 images, and the test set (Test2) with the remaining 100 labeled images. 


\section{Metrics}

The Mean Radial Error (MRE) was used as loss function and the Successful Detection Rate (SDR) regarding the ranges $\{2.0,2.5,3.0,4.0\}$ $[\mathrm{mm}]$, based in the pixel size of images (see Table 2). To compute MRE is first needed to calculate the 2D Euclidean distance between the predicted pixel and the expert's pixel. This distance is computed as follows:

$R=\sqrt{(\Delta X)^{2}+(\Delta Y)^{2}}=\sqrt{\left(x_{p}-x_{o}\right)^{2}+\left(y_{p}-y_{o}\right)^{2}}$

Where:

$\mathrm{R}=$ Euclidean distance between two points.

$\Delta X, \Delta Y=$ Distance in each axis.

$\left(\mathrm{x}_{\mathrm{p}}, \mathrm{y}_{\mathrm{p}}\right)=$ Predicted coordinates.

$\left(x_{o}, \mathrm{y}_{o}\right)=$ Objective coordinates.

The Mean Radial Error is defined as follows:

$$
M R E=\frac{1}{N} \sum_{i=1}^{N}\left\|X_{\text {expertos }}-X_{C N N}\right\|=\frac{1}{N} \sum_{i=1}^{N} R_{i}
$$

Where:

$\mathrm{N}=$ Number of used images belonging the dataset to evaluate.

$X_{\{\text {expertos }}=$ Location of the label selected by health experts. This is the ground truth.

$X_{\{C N N\}}=$ Prediction made by the presented model.

$R_{i}=$ Euclidean distance average of the M cephalometric landmarks to locate, calculated using $R_{i}=\frac{1}{M} \sum_{j=1}^{M} R_{i j}$.

The Successful Detection Rate $p_{z}$ is a metric to indicate the percentage of cephalograms that were identified in a precision range $z$. The SDR is calculated as follows:

$p_{z}=\frac{N_{z}}{N} \times 100 \%=\frac{\left|\left\{i \in \mathbb{N}: R_{i}<z, 1 \leq i \leq N\right\}\right|}{N} \times 100 \%$ (3)
Figure 4. shows a cephalogram marked with the detection ranges.

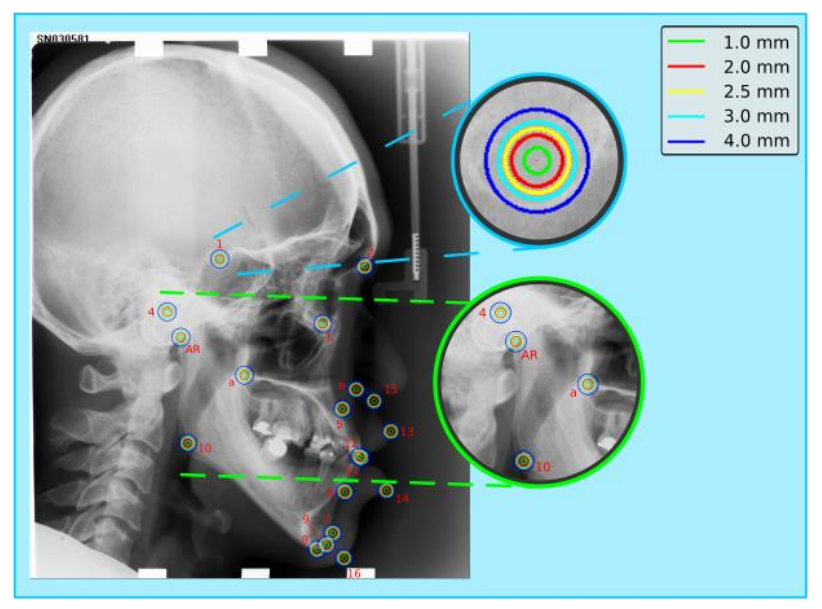

Figure 4 Different marked ranges in comparison with the label made by expert one

\section{Model Architecture}

The final choice of the model's hyperparameters is made using grid search to train the model varying from a table and a range of hyperparameters and pick the ones that offer the best results. The hyperparameters to modify were: Learning rate, training epochs, dropout rate, regularization type, neurons or feature maps in each layer, and model's depth.

The database compression, data loading, and model generation were made using the Python programming language. The $\mathrm{CNN}$ model was created using the Keras high-level API running in TensorFlow 2.3 backend. Table 3 shows the hardware used.

\begin{tabular}{|l|l|}
\multicolumn{1}{|c|}{ Feature } & \multicolumn{1}{c|}{ Value } \\
\hline Model & MSI GF63 \\
\hline Operative System & Windows 10 \\
\hline Processor & Intel core i5 $10^{\text {th }}$ generation. \\
\hline RAM Memory & 16 GB DDR4 \\
\hline GPU & NVIDIA GTX 1650Ti 4GB \\
\hline Storage & 250 GB SSD \\
\hline
\end{tabular}

Table 3 Hardware used to develop the presented model.

The function that generates the model receives tree parameters: Image height, width, and the number of coordinates to predict. The input layer is created using these data and the input image. After the input layer, there are five convolutional blocks, consisting of convolutional layers for feature extraction and MaxPooling layers for dimensionality reduction. Each convolutional block includes "Same" padding, to keep the dimensionality of the output feature map equal to the input.

LÓPEZ-RAMÍREZ, José Luis, CALDERÓN-SASTRE, Enrique, QUINTANILLA-DOMÍNGUEZ, Joel and AGUILERA-GONZÁLEZ, José Gabriel. Automatic cephalometric landmark identification in lateral skull X-Rays using convolutional neural networks. Journal of Engineering Applications. 2021 
Once the convolutional stage is finished, is necessary to vectorize the output to feed the regression step, this is achieved with the Flatten layer. The output of Flatten layer is connected to a Dense layer with 380 neurons, this is, 10 times the number of coordinates to predict.

The output layer is a Densely connected layer with 38 neurons, the same as cephalometric landmarks. This layer has a linear activation function. Table 4 shows the final hyperparameters to build the model, and Figure 5 shows a diagram of the architecture.

\begin{tabular}{|l|r|}
\hline Hyperparameter & \multicolumn{2}{|c|}{ Value } \\
\hline Hidden layers & \multicolumn{2}{|c|}{} \\
\hline Loss function & MRE \\
\hline Optimizer & Nadam with CLR Triangular \\
\hline Learning rate & $0.0001-0.001$ \\
\hline Training epochs & \multicolumn{2}{|}{77} \\
\hline Kernel size & $3 \times 3$ \\
\hline Stride & \multicolumn{2}{|}{1} \\
\hline Padding & "Same" \\
\hline Pooling & Max-Pooling \\
\hline
\end{tabular}

Table 4 Chosen hyperparameters to build the model.

\section{Results}

Graphic 1 shows the loss curve versus training epochs. It is easy to see the influence of CLR in the triangular shape of the graph. Table 5 shows the MRE average results both in validation and test obtained with the presented model.

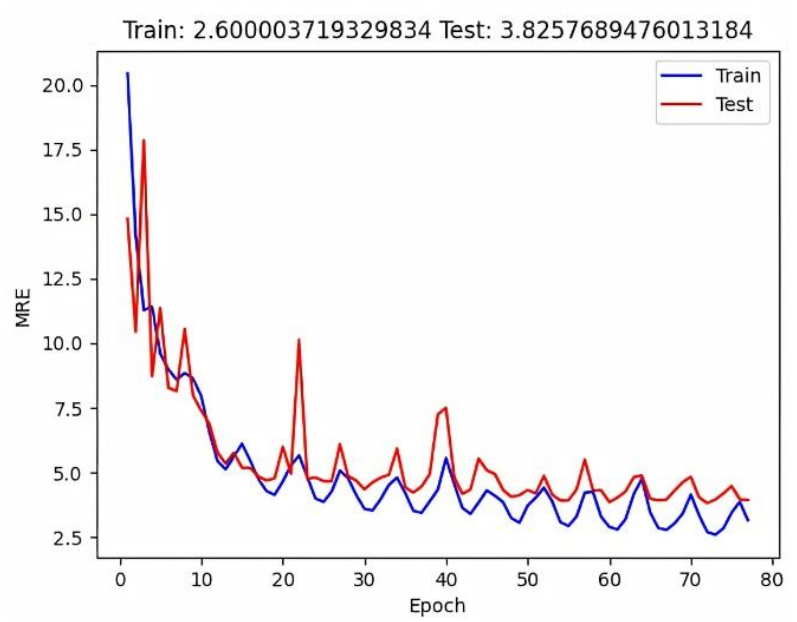

Graphic 1 Curve of loss versus training epochs

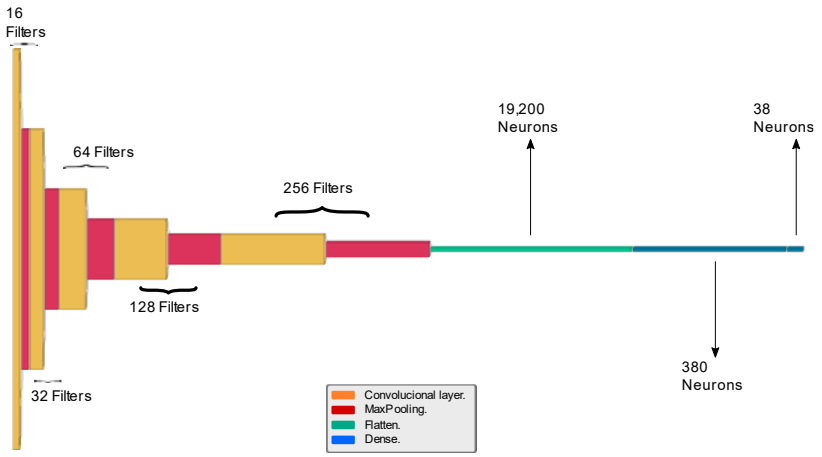

Figure 5 Layer organization of the presented model

\begin{tabular}{|c|c|c|}
\hline \multirow{2}{*}{$\begin{array}{l}\text { Cephalometric } \\
\text { landmark }\end{array}$} & \multicolumn{2}{|c|}{ Average MRE [mm] } \\
\hline & Test1 & Test2 \\
\hline 1.- Sella turcica & 3.94 & 4.22 \\
\hline 2.- Nasion $(\mathrm{N})$ & 3.78 & 4.36 \\
\hline 3.- Orbitale (Or) & 3.16 & 3.67 \\
\hline 4.- Porion $(\mathrm{P})$ & 3.99 & 5.25 \\
\hline 5.- Subspinale & 3.41 & 3.65 \\
\hline 6.- Supramentale & 3.29 & 3.90 \\
\hline 7.- Pogonion (Pog) & 4.51 & 4.46 \\
\hline 8.- Menton $(\mathrm{Me})$ & 4.49 & 4.50 \\
\hline 9.- Gnathion (Gn) & 4.58 & 4.40 \\
\hline 10.- Gonion (Go) & 4.53 & 5.50 \\
\hline $\begin{array}{l}\text { 11.- Lower incisal } \\
\text { incision }\end{array}$ & 3.43 & 3.67 \\
\hline 12.- Upper incisal incision & 3.63 & 3.88 \\
\hline 13.- Upper lip & 3.75 & 4.12 \\
\hline 14.- Lower lip & 3.79 & 4.30 \\
\hline 15.- Point PM or MN & 3.20 & 3.49 \\
\hline 16.- Soft tissue pogonion & 4.43 & 4.49 \\
\hline a.- Posterior nasal spine & 3.04 & 3.64 \\
\hline b.- Anterior nasal spine & 3.47 & 3.49 \\
\hline AR.- Articulate & 4.27 & 5.17 \\
\hline Average & 3.83 & 4.22 \\
\hline
\end{tabular}

Table 5 Average MRE obtained for each cephalometric landmark

From Table 5, we can conclude that the Posterior nasal spine was the best-identified landmark, and Gonion had the worst average results. Figure 6 shows some of the test images labeled with the presented model. Graph 2 shows the distribution of average MRE for the datasets used. As it can be seen, there are some outlier values that strongly impact the calculation of the average MRE.

Regarding the SDR, Table 6 shows the breakdown of the two datasets and their belonging ranges.

\begin{tabular}{|l|r|r|r|r|r|}
\hline \multicolumn{7}{|c|}{ SDR Range (\%) } \\
\multicolumn{2}{|c|}{$\mathbf{2} \mathbf{~ m m}$} & $\mathbf{2 . 5} \mathbf{~ m m}$ & $\mathbf{3} \mathbf{~ m m}$ & $\mathbf{4} \mathbf{~ m m}$ & $\mathbf{5} \mathbf{~ m m}$ \\
\hline Test1 & 2.67 & 12.67 & 32.00 & 60.67 & 86.00 \\
\hline Test 2 & 1.00 & 13.00 & 27.00 & 66.00 & 82.00 \\
\hline
\end{tabular}

Table 6 SDR range for Test 1 and Test 2 datasets QUINTANILLA-DOMÍNGUEZ, Joel and AGUILERA-GONZÁLEZ, José Gabriel. Automatic cephalometric landmark identification in lateral skull X-Rays using convolutional neural networks. Journal of Engineering Applications. 2021 


\section{Future work}

To refine the results obtained with this model, is planned to apply transfer learning to the model and use the state-of-the-art architectures for feature extraction. Transfer learning can help to overcome the lack of labeled images challenge with their powerful feature extraction stages.

As a solution to the variability that means analyzing the cephalogram as a whole by genetic reasons or issues while capturing the radiograph, applying a regression model to every cephalometric landmark to identify can reduce the identification error. To make this, is necessary to extract fixed-size patches.

In addition to the model improvements, a new public database is planned, this will allow us to train the model with a higher quantity of labeled images and increase the generalization ability of the model.

\section{Thanks}
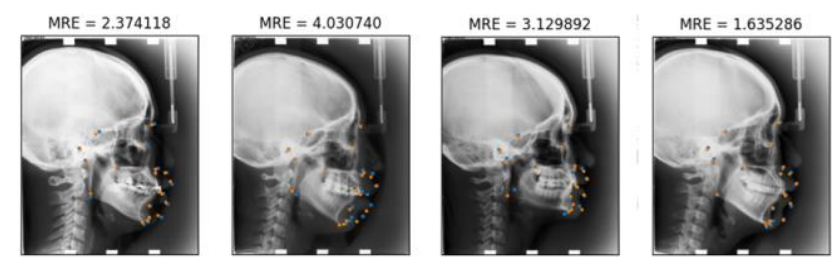

Figure 6 Labeled cephalograms using the presented model
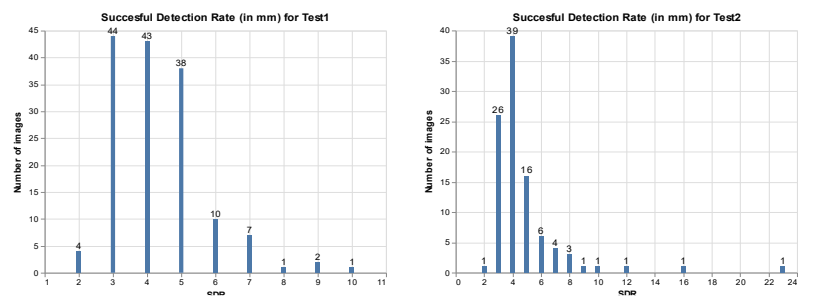

Graphic 2 Average MRE distribution for Test1 and Test2 sets

\section{Conclusions}

The model is a good complementary tool to reduce the identification times by narrowing the search region, although the $2 \mathrm{~mm}$ range was not yet reached.

The model is susceptible to great changes in chin shape, these changes impact directly in the prediction accuracy. Also, the landmarks near the Hindhead (sella turcica, porion, and articulate) are severely affected by the distance between the chin and the inferior border of the cephalogram.

\section{References}

Arpi, J. F. C., Méndez, J. A. T., Zuñiga, P. A. J., Hidalgo, C. D. Z., \& Montiel, R. R. R. (2021).Correlación cefalométrica del mentón y cuerpo mandibular en adultos jóvenes andinos, año 2019. Dilemas contemporáneos: Educación, Política y Valores.

Athanasiou, A. (1995). Orthodontic Cephalometry. Mosby-Wolfe.

Calizana Ayna, R., \& Iglesias Valdivia, F. A. (2021). Prevalencia del biotipo facial según el análisis cefalométrico de Ricketts en radiografías obtenidas en un centro radiológico Arequipa 2020.

Cardillo, J., \& Sid-Ahmed, M. A. (1994). An Image Processing System for Locating Craniofacial Landmarks. IEEE Transactions on Medical Imaging, 13(2), 275-289. https://doi.org/10.1109/42.293920

Chen, Y. T., Cheng, K. S., \& Liu, J. K. (1999). Improving cephalogram analysis through feature subimage extraction. IEEE Engineering in Medicine and Biology Magazine, 18(1), 2531. https://doi.org/10.1109/51.740961

El-Feghi, I., Sid-Ahmed, M. A., \& Ahmadi, M. (2004). Automatic localization of craniofacial landmarks for assisted cephalometry. Pattern Recognition, 37(3), 609-621.

https://doi.org/10.1016/j.patcog.2003.09.002

Foster, T. D. (1990). A textbook of orthodontics. In American Journal of Orthodontics and Dentofacial Orthopedics (3rd ed., Vol. 92, Issue 5). Blackwell Scientific Publications.

Freer, T. W., \& Ulissey, M. J. (2001). Screening mammography with computeraided detection: Prospective study of 12,860 patients in a community breast center. Radiology, 220(3), 781-786.

https://doi.org/10.1148/radiol.2203001282

Fujita, H. (2020). AI-based computer-aided diagnosis (AI-CAD): the latest review to read first. Radiological Physics and Technology, 13(1), 6-19. https://doi.org/10.1007/s12194019-00552-4 
Giger, M. L., Chan, H. P., \& Boone, J. (2008). Anniversary paper: History and status of CAD and quantitative image analysis: The role of Medical Physics and AAPM. Medical Physics, 35(12),

5799-5820.

https://doi.org/10.1118/1.3013555

Gill, D. S., \& Naini, F. B. (2011). Orthodontics : Principles and Practice (1st ed.). John Wiley \& Sons.

Ibragimov, B., Likar, B., Pernuš, F., \& Vrtovec, T. (2014). Automatic cephalometric X-ray landmark detection by applying game theory and random forests. ISBI Int. Symp. Biomed. Imag. 2014, Automat. Cephalometric X-Ray Landmark Detection Challenge, 1-8. http://www-

o.ntust.edu.tw/ cweiwang/celph/paper/bulat.pdf

Ibragimov, B., Likar, B., Pernuš, F., \& Vrtovec, T. (2015). Computerized Cephalometry by Game Theory with Shape- and AppearanceBased Landmark Refinement. Proceedings of the IEEE International Symposium on Biomedical Imaging (ISBI) 2015 - Grand Challenges in Dental X-Ray Image Analysis Automated Detection and Analysis for Diagnosis in Cephalometric X-Ray Image, 1-8. http://www.o.ntust.edu.tw/ cweiwang/ISBI2015 /challenge1/isbi2015_Ibragimov.pdf

Kula, K., \& Ghoneima, A. (2018). Cephalometry in Orthodontics: $2 D$ and $3 D$. Quintessence Publishing Co, Inc.

Leonardi, R., Giordano, D., \& Maiorana, F. (2009). An evaluation of cellular neural networks for the automatic identification of cephalometric landmarks on digital images. Journal of Biomedicine and Biotechnology, 2009. https://doi.org/10.1155/2009/717102

Lévy-Mandel, A. D., Venetsanopoulos, A. N., \& Tsotsos, J. K. (1986). Knowledge-based landmarking of cephalograms. Computers and Biomedical Research, 19(3), 282-309. https://doi.org/10.1016/0010-4809(86)90023-6
Lindner, C., \& Cootes, T. F. (2015). Fully Automatic Cephalometric Evaluation using Random Forest Regression-Voting. Proceedings of the IEEE International Symposium on Biomedical Imaging (ISBI) 2015 - Grand Challenges in Dental X-Ray Image Analysis Automated Detection and Analysis for Diagnosis in Cephalometric X-Ray Image, 1-8. http://www-

o.ntust.edu.tw/ cweiwang/ISBI2015/challenge1 /isbi2015_Lindner-Cootes.pdf

Lopez-Ramirez, J. L., Ruiz-Pinales, J., AviñaCervantes, J. G., Lopez-Rodriguez, P., BeltranHernandez, J. G., \& Ibarra-Manzano, M. A. (2020). Localización de referencias cefalométricas en radiografías laterales de cráneo : Una revisión sistemática Cephalometric References ' Localization in Lateral Skull Radiographs: A Systematic Review. Research in Computing Science, 149(8), 339-352. https://rcs.cic.ipn.mx/2020_149_8/Localizacion de referencias cefalometricas en radiografias laterales de craneo.pdf

Lugo, N. M. O. (2021). Creación de espacio con ortodoncia autoligables para agenesia del lateral superior para reposición con implante. Relato de caso clínico.: Creation of space with selfligating orthodontics for superior lateral agenesis for implant replacement. Clinical casereport. Scientia Oralis Salutem (Ciencia y Salud oral), 2(1), 68-77.

Rakosi, T. (1982). Cephalometric Radiography (1st ed.). Wolfe Medical Publications Ltd.

Requena-Mendoza, A., Cárdenas-Mendoza, M. A., \& Argueta-Figueroa, L. (2021). Manifestaciones clínicas y complicaciones de la Neuropatía Autonómica y Sensorial HereditariaTipo II. CES Odontología, 34(1), 117-126.

Torres Gaitán, Y. (2021). Estudio comparativo de los trazos cefalométricos con el Método Manual Vs el Método Digital (NemoCeph). 
Wang, C. W., Huang, C. T., Hsieh, M. C., Li, C. H., Chang, S. W., Li, W. C., Vandaele, R., Marée, R., Jodogne, S., Geurts, P., Chen, C., Zheng, G., Chu, C., Mirzaalian, H., Hamarneh, G., Vrtovec, T., \& Ibragimov, B. (2015). Evaluation and Comparison of Anatomical Landmark Detection Methods for Cephalometric X-Ray Images: A Grand Challenge. IEEE Transactions on Medical Imaging, 34(9), 1890-1900. https://doi.org/10.1109/TMI.2015.2412951 